\title{
Ophiobolin A, a sesterpenoid fungal phytotoxin, displays different mechanisms of cell death in mammalian cells depending upon the cancer cell origin
}

\author{
RACHEL MORRISON $^{1}$, TIFFANY LODGE ${ }^{2}$, ANTONIO EVIDENTE $^{3}$, ROBERT KISS $^{4}$ and HELEN TOWNLEY ${ }^{1,2}$ \\ ${ }^{1}$ Department of Engineering Science, University of Oxford, Oxford; ${ }^{2}$ Department of Obstetrics and Gynaecology, \\ University of Oxford, John Radcliffe Hospital, Oxford, UK; ${ }^{3}$ Dipartimento di Scienze Chimiche, \\ Universita di Napoli Federico II Complesso Universitario Monte Sant'Angelo, Naples, Italy; ${ }^{4}$ Laboratoire de Cancérologie \\ et de Toxicologie Experimentale, Faculté de Pharmacie, Université Libre de Bruxelles, Brussels, Belgium
}

Received November 4, 2016; Accepted December 15, 2016

DOI: $10.3892 /$ ijo.2017.3858

\begin{abstract}
Herein we have undertaken a systematic analysis of the effects of the fungal derivative ophiobolin A (OphA) on eight cancer cell lines from different tissue types. The $\mathrm{LD}_{50}$ for each cell line was determined and the change in cell size determined. Flow cytometric analysis and western blotting were used to assess the cell death markers for early apoptosis, late apoptosis and necrosis, and the involvement of the caspase signalling pathway. Alterations in calcium levels and reactive oxygen species were assessed due to their integral involvement in intracellular signalling. Subsequently, the endoplasmic reticulum (ER) and mitochondrial responses were investigated more closely. The extent of ER swelling, and the upregulation of proteins involved in the unfolded protein responses (UPR) were seen to vary according to cell line. The mitochondria were also shown to behave differently in response to the OphA
\end{abstract}

Correspondence to: Dr Helen Townley, Department of Engineering Science, University of Oxford, Parks Road, Oxford OX1 3PJ, UK E-mail: helen.townley@eng.ox.ac.uk

Abbreviations: OphA, ophiobolin A; AV, Annexin V; BKCa, big conductance $\mathrm{Ca}^{2+}$-activated $\mathrm{K}^{+}$channel; CaM, calmodulin; CM-H ${ }_{2}$ DCFDA, 2',7'-dichlorodihydrofluorescein diacetate; DAPI, 4',6-diamidino-2-phenylindole; DMEM, Dulbecco's modified Eagle's medium; ER, endoplasmic reticulum; FITC, fluorescein isothiocyanate; FR, folate receptor; GBM, glioblastoma multiforme; MDR, multidrug resistant; MOMP, mitochondrial outer membrane permeabilization; MPT, mitochondrial permeability transport; PARP, poly(ADP) ribose polymerase; PBS, phosphate-buffered saline; PERK, protein kinase-like receptor kinase; PI, propidium iodide; PS, phosphatidyl serine; ROS, reactive oxygen species; SDS, sodium dodecyl sulphate; SphA, sphaeropsidin A; TMRM, tetramethylrhodamine methyl ester; TRITC, tetramethyl rhodamine; UPR, upregulated protein response

Key words: ophiobolin, cancer, apoptosis, necrosis, mitochondria in the different cell lines in terms of the change in membrane potential, the total area of mitochondria in the cell and the number of mitochondrial bifurcations. The data obtained in the present study indicate that the cancer cell lines tested are unable to successfully activate the ER stress/UPR responses, and that the mitochondria appear to be a central player in OphA-induced cancer cell death.

\section{Introduction}

The increase in the incidence of various types of cancers associated with dismal prognoses, such as gliomas (1) and melanomas (2) has not been paralleled by improved therapeutic options. A large proportion of these cancer patients fail to respond to conventional chemotherapy because of the intrinsic resistance of their cancer to pro-apoptotic stimuli and/or the acquisition of multidrug (MDR) phenotype during chronic chemotherapy $(1,2)$. To improve the arsenal of chemotherapeutics we have looked to natural products which can provide a rich source of novel compounds with wide structural and functional diversity, biochemical specificity and desirable molecular properties (3). Consequently, in the present study we have further investigated the compound ophiobolin A (OphA) which has been shown to exhibit growth inhibitory activity in vitro in A549 non-small cell lung cancer (4), SKMEL28 melanoma (4), Hs683 and U373 glioma (5-7), RD rhabdomyosarcoma (8) and OVCAR3 ovarian cancer (9) cell lines. OphA also displays in vivo anticancer activity in the murine B16F10 melanoma (6) and in a human glioma (10) models.

OphA is a phytotoxin produced by the fungal pathogen Drechslera gigantea and other Bipolaris spp $(11,12)$. The sesterterpene-type compound (C25) is one of a group of over 25 Ophiobolin analogues (13), which are characterized by the unique 5-8-5 carbotricyclic skeleton (Fig. 1).

Historically, much research has focussed on the effects of OphA on plant tissues, which includes rapid disorganization of the cell membrane resulting in electrolyte and sugar leakage and inhibition of calmodulin-activated cyclic nucleotide phosphodiesterase. The phytotoxin is also known to bind and irreversibly antagonize calmodulin and blocks the activation 


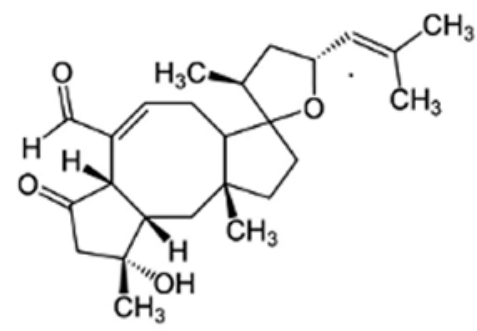

Figure 1. Chemical structure of ophiobolin A.

of calmodulin-dependent phosphodiesterase with an $\mathrm{IC}_{50}$ value of $9 \mu \mathrm{M}$ (14) by binding covalently to conserved lysine residues $(13,15)$. However, while the mode of action has been well studied in plants, the interaction of OphA with mammalian cells is not well understood. We have observed that when tested on eight cancer cell lines, concentrations $<1 \mu \mathrm{M}$ OphA inhibited growth by $50 \%$ after 3 days of culture irrespective of their multidrug resistance (MDR) phenotypes and their resistance levels to pro-apoptotic stimuli (6). It is, thus, unlikely that ophiobolin A exerts these in vitro growth-inhibitory effects in cancer cells through the sole activation of pro-apoptotic processes. We have also shown that OphA induces paraptosislike cell death in glioblastoma multiforme (GBM) cells, with concomitant vacuolization that may occur from the swelling and fusion of mitochondria and/or endoplasmic reticulum, without the activation of caspases (7). Other studies have shown that in mouse leukaemia cells (16) cell death proceeds via an apoptotic mechanism, and also in a rhabdomyosarcoma cell line (RD) with microvesicle release (8).

Since OphA targets calmodulin (CaM) in plant cells, a similar mechanism could operate in mammalian cells. It is known that tumour cells have anomalous concentrations of $\mathrm{CaM}$ and other calcium binding proteins; and this can modify the ways in which calcium is mobilized, with important implications for tumour development and progression $(17,18)$. Increases in intracellular $\mathrm{Ca}^{2+}$ trigger the formation of a $\mathrm{Ca}^{2+} / \mathrm{CaM}$ complex, as monitored in intact cells, followed by modulation of the functionality of the target proteins $(19,20)$. The transient increase in the concentration of free $\mathrm{Ca}^{2+}$ in the cytosol and its spread to the nucleus upon cell activation by a broad range of stimuli including mitogenic factors and other agonists is recognized as the principal event responsible for the initiation of many signal transduction processes (21).

Cell death can be triggered by a range of intracellular stresses including cytosolic $\mathrm{Ca}^{2+}$ overload, DNA damage, oxidative stress and the accumulation of misfolded proteins (22). We have therefore investigated the effect of OphA to induce these stresses and how they affect the mitochondria and endoplasmic reticulum. A systematic study of the effects on cell organelles was used to investigate the modes of OphA-induced cell death in tumour cell lines of differing histological origin.

\section{Materials and methods}

Ophiobolin A preparation. Ophiobolin A (OphA) was obtained as white crystals from Drechslera gigantea culture filtrates according to the procedure previously reported (11). The purity of OphA was determined by RP-HPLC-UV to be $>95 \%$. Stock
OphA solutions were prepared by dissolving OphA in ethanol (Sigma-Aldrich) at a concentration of $2500 \mu \mathrm{M}$ and further dilutions were carried out in phosphate-buffered saline (PBS; Sigma-Aldrich).

Cell culture. The biological effect of OphA was tested in vitro on 8 cancer cell lines obtained from the American Type Culture Collection (ATCC; Manassas, VA, USA). These 8 cell lines include the RD (ATCC code CCL-136) and RH30 (ATCC code CRL-7763) rhabdomyosarcoma, the MCF 7 (ATCC code HTB-22) and MDA-MB-231 (ATCC code HTB-26) breast cancer, the HeLa (ATCC code CCL-2) cervix cancer, the KB 3-1 (ACC code 158) epidermoid cancer, the U-87 MG glioma (ATCC code HTB-14) and the U2OS osteosarcoma (ATCC code HTB-96) models. Cells were grown in growth medium (Dulbecco's modified Eagle's medium (DMEM; Sigma-Aldrich) supplemented with $10 \%$ fetal calf serum (FCS; Sigma-Aldrich), $2 \mathrm{mM}$ L-glutamine (SigmaAldrich), $100 \mathrm{U} / \mathrm{ml}$ penicillin (Sigma-Aldrich) and $0.1 \mathrm{mg} / \mathrm{ml}$ streptomycin (Sigma-Aldrich) and incubated at $37^{\circ} \mathrm{C}$ in a $5 \%$ $\mathrm{CO}_{2}$ atmosphere. Cells were passaged every three to four days.

Crystal violet cell viability staining. Cells were seeded in 96-well plates at $1 \times 10^{4}$ cells/well in growth media and left overnight in the incubator for the cells to adhere. The following day cells were treated for $24 \mathrm{~h}$ with $0-100 \mu \mathrm{M}$ OphA. After treatment, the media on the cells was removed and the cells were washed in PBS twice. Cells were fixed in $100 \mu 1$ of $1 \%(\mathrm{v} / \mathrm{v})$ glutaraldehyde (aq; Sigma-Aldrich) for $30 \mathrm{~min}$ and stained with $100 \mu 1$ of $0.5 \%$ (w/v) crystal violet solution (aq; Sigma-Aldrich) for at least $1 \mathrm{~h}$. The plate was washed with water, dried overnight and cells were solubilized using $150 \mu \mathrm{l}$ of solubilising solution [1\% (w/v) sodium dodecyl sulphate (SDS; Fisher Fisher Scientific) and 10\% (v/v) acetic acid (Sigma-Aldrich)]. The absorbance of the solution was measured at $590 \mathrm{~nm}$ using a Tecan Infinite F200 microplate reader. Samples were blank corrected and expressed as a percentage of the control cell viability. Experiments were performed in triplicate and repeated on three separate occasions.

Staining of cell mitochondria using MitoTracker ${ }^{\circledR}$ Green and tetramethylrhodamine. Cells were seeded in 24-well plates at $8 \times 10^{4}$ cells/well in growth media and left overnight in the incubator for the cells to adhere. The following day cells were pre-stained with $200 \mathrm{nM}$ MitoTracker ${ }^{\circledR}$ Green (Invitrogen), $50 \mathrm{nM}$ tetramethylrhodamine methyl ester (TMRM; Invitrogen) and $10 \mathrm{nM}$ Hoechst for $30 \mathrm{~min}$. After staining was confirmed cells were washed in fresh media and treated for $1 \mathrm{~h}$ with either i) PBS; ii) $1 \mu \mathrm{M}$ OphA; or iii) $10 \mu \mathrm{M}$ OphA in triplicate. The cells were imaged with a Motic AE31 microscope equipped with a mercury lamp and filters for DAPI (Ex. 345 nm, Ex. 455 nm), TRITC (Ex. 547 nm, Em. 572 nm) and FITC (Ex. 495 nm, Em. 519 nm). Experiments were performed in triplicate and repeated on at least two separate occasions.

Staining of reactive oxygen species in the cells using 2',7'-dichlorodihydrofluorescein diacetate (CM- $\left.\mathrm{H}_{2} \mathrm{DCFDA}\right)$. Cells were seeded in 24 -well plates at $8 \times 10^{4}$ cells/well in growth media and left overnight in the incubator for the cells to adhere. The following day cells were pre-stained with $1 \mu \mathrm{M}$ 
CM-H $\mathrm{H}_{2} \mathrm{DCFDA}$ (Invitrogen) for $45 \mathrm{~min}$. After staining was confirmed, cells were washed in fresh media and treated for $1 \mathrm{~h}$ with either: i) PBS; ii) $1 \mu \mathrm{M}$ OphA; or iii) $10 \mu \mathrm{M}$ OphA in triplicate. Cells were imaged using a Motic AE31 microscope with filters for FITC. Experiments were performed in triplicate and repeated on at least two separate occasions.

Cellular calcium concentration. Cells were seeded in 96-well plates at $1 \times 10^{4}$ cells/well in growth media and left overnight in the incubator for the cells to adhere. The following day cells were washed in PBS and then pre-stained with $2 \mu \mathrm{M}$ Fluo 4 (Invitrogen) in PBS for $1 \mathrm{~h}$. After staining was confirmed cells were washed in PBS twice and then the following treatments were applied: i) PBS; ii) $1 \mu \mathrm{M} \mathrm{OphA}$; and iii) $10 \mu \mathrm{M}$ OphA. The change in Fluo4 fluorescence over $6 \mathrm{~h}$, at 5-min intervals, was measured using a Tecan Infinite F200 series microplate reader equipped with filters for FITC (Ex. 495 nm, Em. 519 nm). Samples were blank corrected and the maximum slope of the linear region of each curve was calculated. Experiments were performed in triplicate on two separate occasions.

Flow cytometry. For all flow cytometric experiments, cells were seeded in either 12 - or 24 -well plates at $15 \times 10^{4}$ or $8 \times 10^{4}$ cells/well respectively in growth media and left overnight in the incubator for the cells to adhere. Cells were treated with OphA and samples were prepared by collecting the supernatant containing the non-adherent cells while the adherent cells were washed and trypsinized (Trypsin-EDTA; Sigma-Aldrich) and then combined with the first supernatant. The combined cells were then centrifuged and washed in PBS or Annexin V binding buffer twice, before being resuspended in $50 \mu 1$ of PBS or Annexin V binding buffer. Cells were stained with dyes of interest. Subsequently, $200 \mu \mathrm{l}$ of PBS or Annexin V binding buffer was added to the cells and then at least 10,000 cells from the samples were analysed using a BD FACSCalibur flow cytometer. Flowing software version 2 (www.flowingsoftware. com) was used to visualise the cell data as dot and histogram plots and subsequently to analyse the data. Experiments were performed in triplicate and repeated on at least two separate occasions.

Cell size. Cells were treated for $24 \mathrm{~h}$ with either: i) PBS; ii) $1 \mu \mathrm{M}$ OphA; iii) $10 \mu \mathrm{M}$ OphA; or iv) $100 \mu \mathrm{M}$ in triplicate. The change in cell size was investigated by monitoring the change in median forward scatter (FSC) signal intensity. Forward-scattered light is proportional to cell-surface area or size, and is a measurement of mostly diffracted light which is independent of fluorescence.

Quantification of mitochondrial membrane potential using TMRM. Cells were treated for $1 \mathrm{~h}$ with either: i) PBS; ii) $1 \mu \mathrm{M}$ OphA; or iii) $10 \mu \mathrm{M}$ OphA in triplicate. Cells were stained with $500 \mathrm{nM}$ MitoTracker ${ }^{\circledR}$ Green and $50 \mathrm{nM}$ TMRM for $30 \mathrm{~min}$ at room temperature. The change in mitochondrial membrane potential was investigated by monitoring the change in median TMRM fluorescence intensity.

Quantification of reactive oxygen species in the cells using $C M-H_{2} D C F D A$. Cells were treated for $1 \mathrm{~h}$ with either; i) PBS; ii) $1 \mu \mathrm{M}$ OphA; or iii) $10 \mu \mathrm{M}$ OphA, in triplicate. Cell were stained with $1 \mu \mathrm{M} \mathrm{CM}-\mathrm{H}_{2}$ DCFDA and $120 \mathrm{mM}$ PI for $45 \mathrm{~min}$ at room temperature. PI stains cells with a permeable membrane. The reactive oxygen species production was investigated by monitoring the change in median $\mathrm{CM}-\mathrm{H}_{2} \mathrm{DCFDA}$ fluorescence intensity of the live cells (PI negative).

Quantification of phosphatidylserine translocation to the outer membrane. Annexin V binds PS and can be used as a probe for cell death via an apoptotic pathway. Combination of Annexin V and PI (which stains the DNA of cells with a permeable membrane, i.e. necrotic cells) can determine early apoptotic cells which are Annexin V positive and PI negative $\left(\mathrm{AV}^{+} / \mathrm{PI}\right)^{-}$. Late apoptotic cells are $\mathrm{AV}^{+} / \mathrm{PI}^{+}$and necrotic cells are $\mathrm{AV}^{-} / \mathrm{PI}^{+}$. Cells were treated for $24 \mathrm{~h}$ with either; i) $\mathrm{PBS}$; ii) $1 \mu \mathrm{M}$ OphA; iii) $10 \mu \mathrm{M}$ OphA; or iv) $100 \mu \mathrm{M}$ in triplicate. Cells were dyed with $2.5 \mu$ l of APC-Annexin V (BioLegend, San Diego, CA, USA) to probe phosphatidylserine translocation onto the outer membrane, and $150 \mathrm{mM}$ PI. The number of cells which showed positive APC Annexin $\mathrm{V}\left(\mathrm{AV}^{+}\right)$staining with negative $\mathrm{PI}\left(\mathrm{PI}^{-}\right)$staining and those with an $\mathrm{AV}^{+} / \mathrm{PI}^{+}$and $\mathrm{AV}^{-} / \mathrm{PI}^{+}$, pattern were recorded. The $\mathrm{AV}^{+} / \mathrm{PI}^{-}$cells are in early apoptosis, while $\mathrm{AV}^{+} / \mathrm{PI}^{+}$cells are in late apoptosis. $\mathrm{AV}^{-} / \mathrm{PI}^{+}$ cells are necrotic.

Automated high throughput image acquisition and analysis. Cells were seeded in 96-well plates at $7.5 \times 10^{3}$ cells/well in growth media and left overnight in the incubator for the cells to adhere. The following day cells were treated for $24 \mathrm{~h}$ with either: i) PBS or ii) $1 \mu \mathrm{M}$ OphA, in triplicate. Cells were then washed in PBS, fixed in 4\% paraformaldehyde (PFA) for 15 min, washed again in PBS and left in PBS until staining. The endoplasmic reticulum (ER) was stained with calnexin (Santa Cruz Biotechnology), the mitochondria with TOM20 (Santa Cruz Biotechnology) and the nucleus with DAPI. Alexa Fluor secondary antibodies were used to stain the ER green (Alexa Fluor 488; Life Technologies) and the mitochondria red (Alexa Fluor 488; Life Technologies). Staining was performed within seven days of fixing.

Image acquisition was performed using an automated imaging platform IN Cell Analyzer 1000 (GE Healthcare Life Sciences) equipped with a Nikon Fluor ELWD 40 x 0.6 objective. Six fields of view were taken from each well in all three fluorescence modes (FITC, TRITC and DAPI). Raw images were processed and parameters obtained using a customised protocol in the IN Cell Developer Toolbox software (GE Healthcare Life Sciences). Cells were segmented using DAPI (cell nuclei) and properties of the endoplasmic reticulum and mitochondria were obtained. The total area of the endoplasmic reticulum and the mitochondria and the mitochondrial size and branching network were investigated. Experiments were performed in triplicate and repeated on at least two separate occasions.

Immunoblotting. Cells were seeded in T25 flasks at $75 \times 10^{4}$ cells/flask in growth media and cells were allowed to adhere to the flask overnight in the incubator. The following day cells were treated for $24 \mathrm{~h}$ with either: i) PBS; or ii) $1 \mu \mathrm{M}$ OphA. Cell lysates were prepared using $200 \mu \mathrm{l}$ of cOmplete Lysis-M kit supplemented with protease and phosphatase inhibitors (Roche Diagnostics) and scraping the cells from the bottom 
Table I. Summary of the mutations found in the cell lines used in the present study.

\begin{tabular}{|c|c|c|c|}
\hline Cell line & Tissue type & Mutation & Ref. \\
\hline RD & Muscle & NRAS, TP53 & (26) \\
\hline RH30 & Muscle & TP53 & (27) \\
\hline MDA-MB-231 & Breast & CDKN2A, KRAS, TP53 & $(26)$ \\
\hline MCF 7 & Breast & CDKN2A, PIK3CA, caspase-3 & $(26,28)$ \\
\hline HeLa & Cervix & Mutations in cell cycling and DNA repair signalling pathways & (29) \\
\hline KB 3-1 & HeLa contaminant & Likely to be similar to HeLa & \\
\hline $\mathrm{U} 2 \mathrm{OS}$ & Bone & Wild-type TP53A & (30) \\
\hline $\mathrm{U}-87 \mathrm{MG}$ & Brain & CDKN2A, PTEN & (26) \\
\hline
\end{tabular}

of the flasks. Cell lysates were centrifuged to separate cell debris, and the protein concentration of the supernatant was determined using the BCA assay (Pierce). Protein $(10 \mu \mathrm{g}$ per sample) was mixed with loading buffer, boiled for $4 \mathrm{~min}$ and subjected to SDS-PAGE at $120 \mathrm{~V}$ followed by a transfer to PVDF membrane for $50 \mathrm{~min}$ at $30 \mathrm{~V}$. Membranes were blocked with $5 \%$ milk in TBST for $1 \mathrm{~h}$ at room temperature and subsequently probed with BiP/GRP78 (1:1,000), PDI $(1: 1,000)$, CHOP $(1: 1,000)$, cleaved PARP $(1: 1,000)$ or $\beta$-actin $(1: 100,000)$ as a primary antibody overnight at $4^{\circ} \mathrm{C}$. Horseradish peroxidase-conjugate secondary antibodies were used and blots were revealed by ECL. Experiments were performed on two separate occasions.

Statistical analysis. The cell viability data and flow cytometric data are presented as mean \pm standard deviation (SD) of triplicate samples. The high throughput image acquisition and analysis data are presented as mean \pm standard error of the mean (SE) of each cell measured due to the high, $>432$, number of cells per sample imaged. Statistical analysis was performed by a two tailed Students t-test in Excel. $\mathrm{P}<0.05$ was taken as the criteria for statistical significance.

\section{Results}

Determination of the lethal dose $\left(L D_{50}\right)$ after $24 \mathrm{~h}$ of cell culture. A number of cell lines from differing tissues of origin were used to investigate the effects of OphA. We have used the breast cancer cell lines MCF 7 and MDA-MB-231 which differ in their metastatic potential; MCF 7 is non-invasive while MDA-MB-231 is an invasive breast cancer (23). The sarcoma cell lines used were the osteosarcoma line U2OS and the rhabdomyosarcoma lines RD and RH30. The latter are representative of the two major histological subtypes, eRMS and the more metastatic aRMS (24). The cervical cancer cell line HeLa and the derived cell line KB 3-1 were also investigated. The cervical cell lines differ in the expression of the folate receptor (FR) with HeLa being FR (+), whilst KB 3-1 overexpresses FR (++) (25). U-87 MG was also investigated as an example of glioblastoma, being the most common primary malignant brain tumour. The mutations found in the cancerous cells lines are shown in Table I.

OphA was assessed in terms of its ability to effect cell death in all eight cell lines using the crystal violet test. Data was plotted and fitted to logarithmic curves (except HeLa which showed a sigmoidal fit) and the $\mathrm{LD}_{50}$ calculated from the trendline equation. The $\mathrm{LD}_{50}$ values ranged from 0.5 to $5.8 \mu \mathrm{M}$ for MDA-MB-231 and HeLa cells, respectively (Fig. 2).

OphA affects cancer cell size. In all the cell lines tested OphA caused the cells to round up and become more spherical. Representative bright field images of RH30 rhabdomyosarcoma cells treated with 1-100 $\mu \mathrm{M}$ OphA are provided as an example in Fig. 3A.

Cells are known to change size during cell death: for example, cells are known to shrink during apoptosis while they are known to swell during necrosis (31). Changes in cell size, after $24 \mathrm{~h}$ treatment with OphA, were monitored using the FSC channel on the flow cytometer. The data are shown as the median cell size and expressed as the change in size compared to the same cell line without OphA. After $24 \mathrm{~h}$ of OphA treatment either cell shrinkage, cell swelling or no change in cell size was observed depending on the cell line treated (Fig. 3B). There was little difference in the size of the cells after $24 \mathrm{~h}$ treatment at the lower concentration. However, treatment with $10 \mu \mathrm{M}$ OphA showed a highly statistically significant decrease in size for RD, RH30, MDA-MB-231 and MCF cells. There was a significant increase in size for HeLa cells and U2OS cells. Treatment with the lower concentration of $1 \mu \mathrm{M}$ OphA 

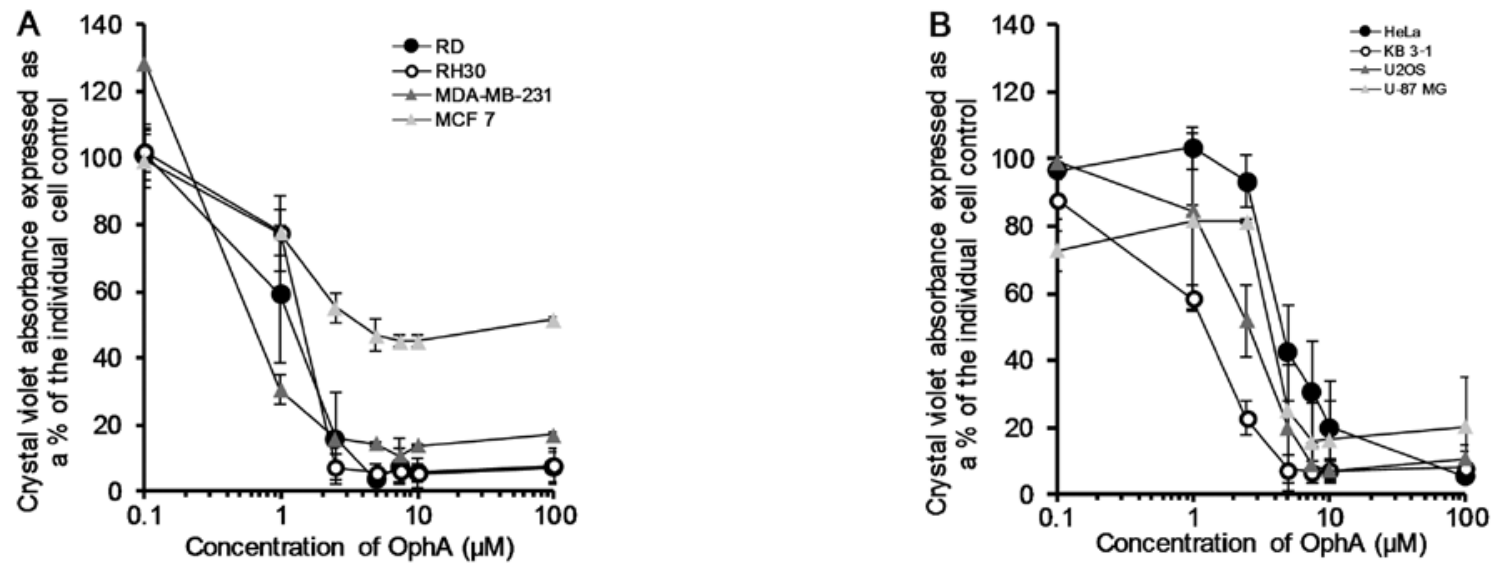

Figure 2. OphA-induced cell death in cell viability results after treatment with 0 to $100 \mu \mathrm{M}$ OphA using crystal violet staining for all the cell lines used in the study. Data are presented as the mean \pm SD of triplicate samples, expressed as a percentage of the control cells absorbance.
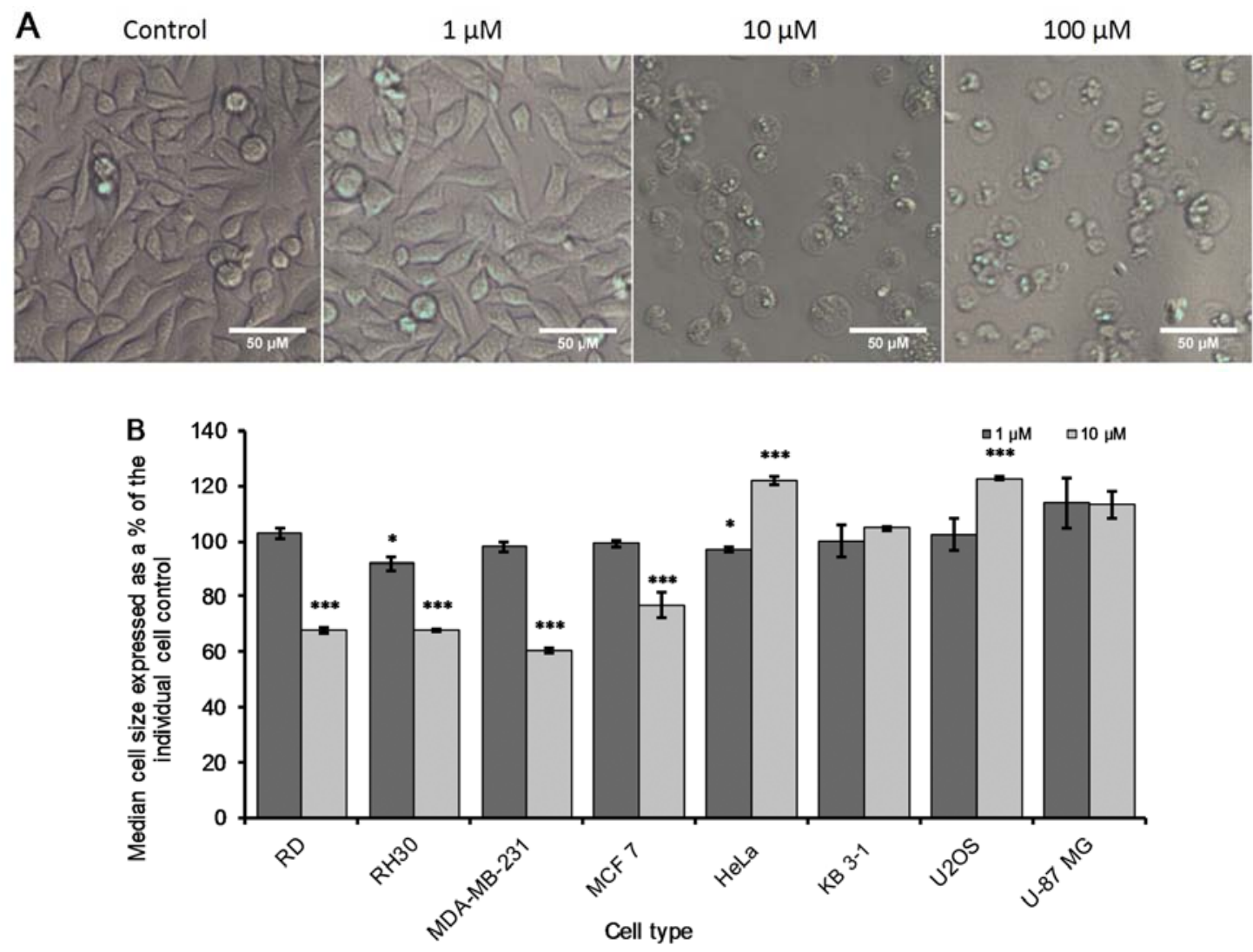

Figure 3. (A) Representative bright field microscope images of RH30 cells treated with 0-100 $\mu$ M OphA: i) RH30 cells treated with PBS as a control; ii) RH30 cells treated with $1 \mu \mathrm{M}$ OphA showing no significant difference in morphology to the control. RH30 cells treated with: iii) $10 \mu \mathrm{M}$ OphA; and (iv) $100 \mu \mathrm{M}$ OphA, both showing the cells rounding up and becoming more spherical. All scale bars are $50 \mu \mathrm{m}$. (B) OphA causes both cell shrinkage and cell swelling depending on the cell line. Results for each cell line showing the change in cell size after $24 \mathrm{~h}$ of treatment with 0-10 $\mu \mathrm{M}$ OphA. Data are presented as mean \pm SD of triplicate samples for each individual cell line expressed as a percentage of the individual cell control. Significance was tested using a two tailed t-test compared to the untreated cells for each cell line $\left({ }^{*} \mathrm{P} \leq 0.05,{ }^{* * * *} \mathrm{P} \leq 0.005\right)$.

for $24 \mathrm{~h}$ resulted in little significant change in cell size for any of the cell lines tested (Fig. 3B).

Pro-apoptotic vs. necrotic effects induced by OphA in cancer cells. Phosphatidylserine (PS) is an important phospholipid membrane component. The PS is held facing the cytosolic (inner) cell membrane by the enzyme flippase. When a cell undergoes apoptosis it is no longer restricted to the cytosolic domain and is free to flip to the extracellular surface. As such, flow cytometry was used to quantify these $\mathrm{AV}^{+} / \mathrm{PI}^{-}$, $\mathrm{AV}^{+} / \mathrm{PI}^{+}$and $\mathrm{AV}^{-} / \mathrm{PI}^{+}$cancer cells after $24 \mathrm{~h}$ of OphA treatment. OphA-induced early apoptotic effects $(10 \mu \mathrm{M})$ were the most pronounced $(\mathrm{P}<0.005)$ in RD, RH30 and MDA-MB-231 cells (Fig. 4A). The remaining five cancer cell lines showed a much smaller but still significant increase in the percentage of early apoptotic cells $\left(\mathrm{AV}^{+} / \mathrm{PI}^{-}\right)$compared to the untreated cells 

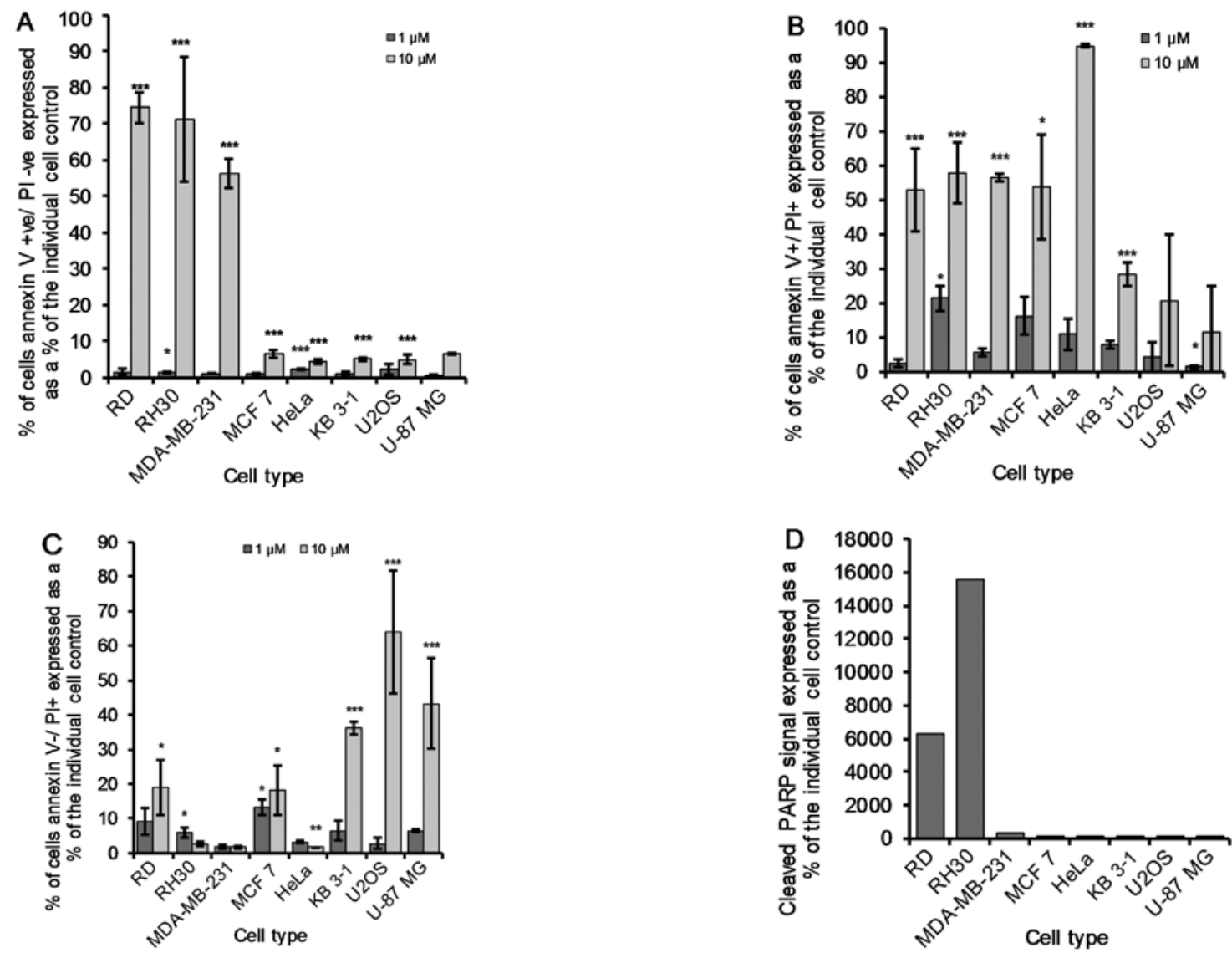

Figure 4. Cell death status in the presence of OphA. Flow cytometry was used to assess whether cells showed a positive or negative signal with Annexin $\mathrm{V}$ (AV) and propidium iodide (PI) after OphA treatment. (A) $\mathrm{AV}^{+} / \mathrm{PI}^{-}(\mathrm{B}) \mathrm{AV}^{+} / \mathrm{PI}^{+}$(C) $\mathrm{AV}^{-} / \mathrm{PI}^{+}$. Results for each cell line. Data are presented mean $\pm \mathrm{SD}$ of triplicate samples for each individual cell line as a percentage of the untreated cells. Significance was tested using a two tailed t-test compared to the untreated cells for each cell line $\left({ }^{*} \mathrm{P} \leq 0.05,{ }^{* *} \mathrm{P} \leq 0.01,{ }^{* * *} \mathrm{P} \leq 0.005\right)$. (D) Cleaved PARP signal as assessed by western blot analysis in the presence of $1 \mu \mathrm{M}$ OphA shown as percentage of untreated cells for each individual cell line.
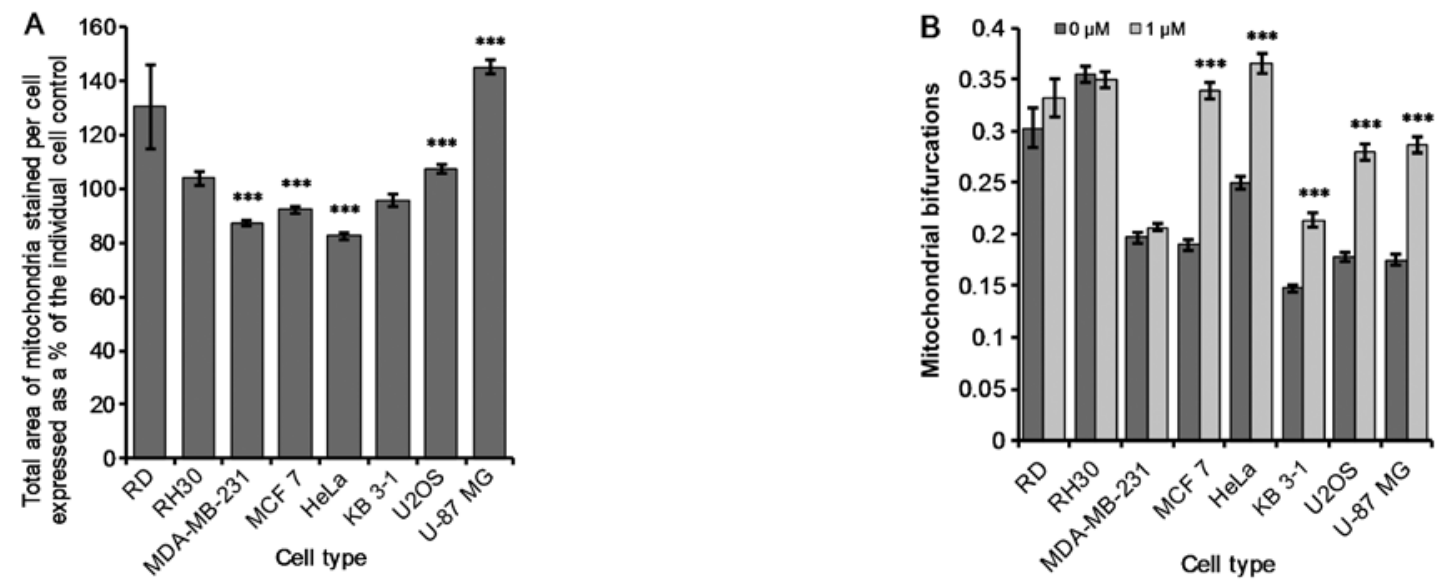

Figure 5. Effect of ophiobolin A on mitochondria measured using an automated high throughput image acquisition and analysis system (IN Cell ${ }^{\mathrm{TM}}$ ). Results showing (A) the change in area of the mitochondria per cell. (B) The number of mitochondrial bifurcations. Data are presented as mean \pm SD of triplicate samples for each individual cell line expressed as (A) a percentage of the untreated cells, (B) raw data. Significance was tested using a two tailed t-test compared to the untreated cells for each cell line ( $\left.{ }^{*} \mathrm{P} \leq 0.05,{ }^{* * *} \mathrm{P} \leq 0.005\right)$.

(Fig. 4A). The $\mathrm{LD}_{50}$ values of all the cancer cell lines under study are $<5 \mu \mathrm{M}$ (Fig. 2). Fig. 4A shows that $10 \mu \mathrm{M}$ OphA induces $<20 \%$ of early apoptosis in these five remaining cancer cell lines (MCF 7, HeLa, KB 3-1, U2OS and U-87 MG). OphA $(10 \mu \mathrm{M})$ induced late apoptosis $\left(\mathrm{AV}^{+} / \mathrm{PI}^{+}\right)$in all cell lines under study, but as previously seen (early apoptotic effects; Fig. 4A) the effect was less marked in KB 3-1, U2OS and U-87 MG cancer cells (Fig. 4B). It was clear, however, that the KB 3-1, U2OS and U-87 MG cancer cells were the most sensitive to OphA-induced necrotic ( $\left.\mathrm{AV}^{-} / \mathrm{PI}^{+}\right)$effects (Fig. 4C).

Of note, three of the most sensitive cancer cell lines in terms of OphA-induced decrease in cell size, i.e. RD, RH30 

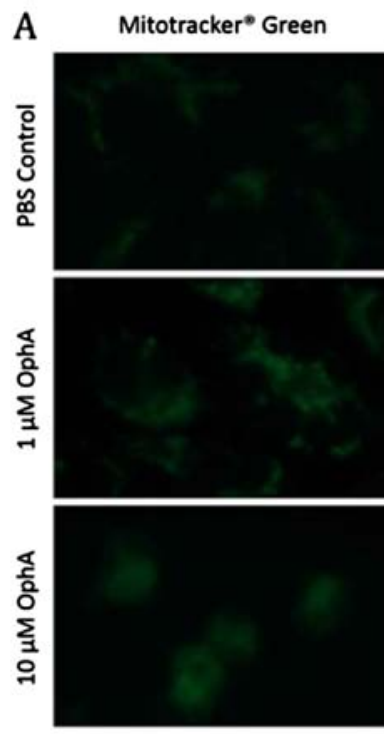

B

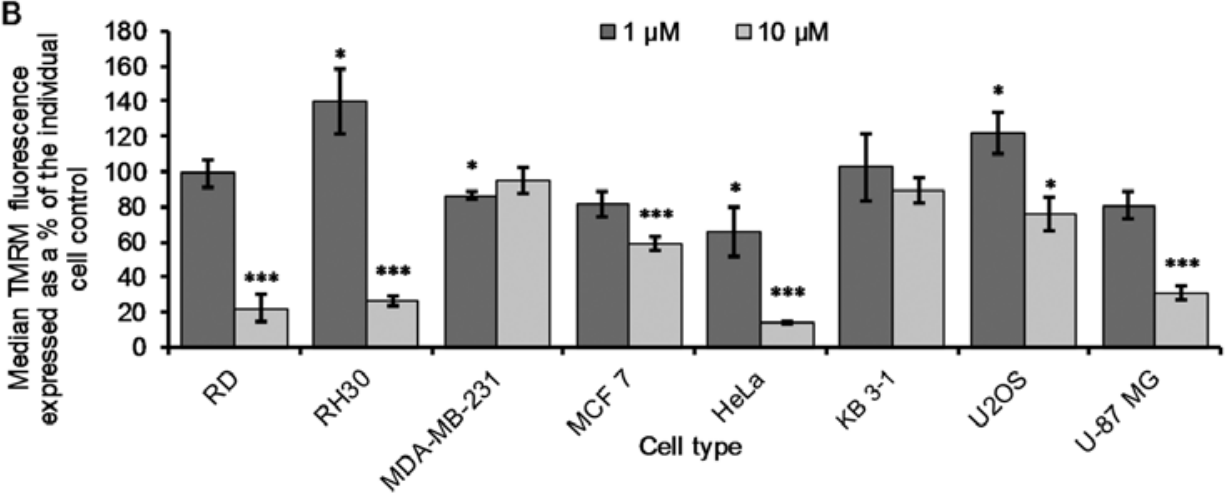

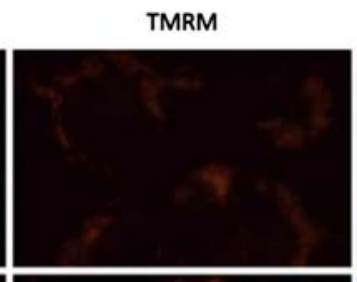
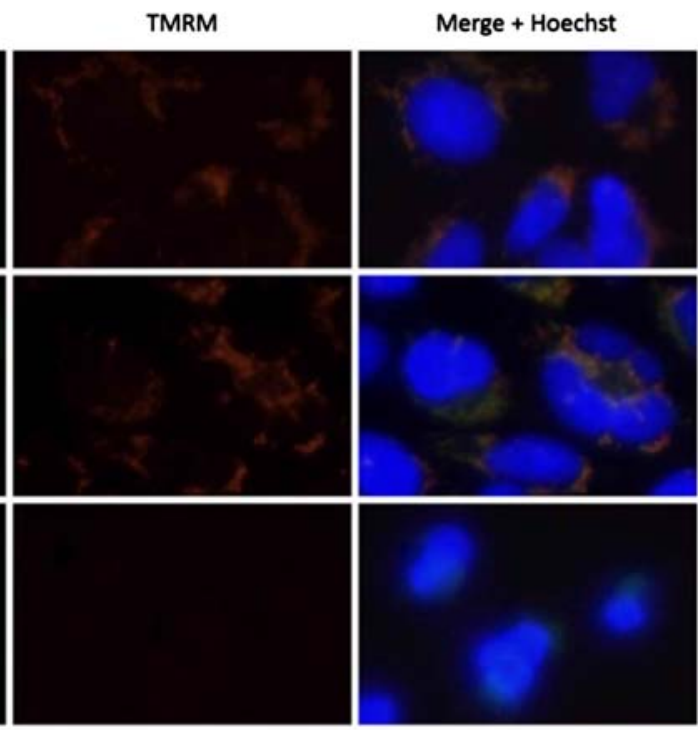

Figure 6. Effect of OphA on mitochondrial membrane potential ( $\Delta \psi \mathrm{m})$ measured using tetramethylrhodamine (TMRM). (A) Immunofluorescence images of RD cells treated for $1 \mathrm{~h}$ with 1 and $10 \mu \mathrm{M}$ OphA and dyed with MitoTracker ${ }^{\circledR}$ Green, staining all the mitochondria; TMRM staining the active mitochondria; and Hoechst staining the cell nucleus. (B) Flow cytometric results for each cell line showing the change in TMRM fluorescence as an indicator for $\Delta \psi m$ after $1 \mathrm{~h}$ treatment with 1 and $10 \mu \mathrm{M}$ OphA OphA. Data are presented as mean \pm SD of triplicate samples for each individual cell line expressed as a percentage of the untreated cells. Significance was tested using a two tailed t-test compared to the untreated cells for each line $\left({ }^{*} \mathrm{P} \leq 0.05,{ }^{* * *} \mathrm{P} \leq 0.005\right)$.

and MDA-MB-231 (Fig. 3B) were also the most sensitive to the OphA-induced early apoptotic effects (Fig. 4A). In the same manner of the four cancer cells lines in which OphA did not induce a decrease in terms of cell size (HeLa, KB 3-1, U2OS and U-87 MG; Fig. 3B), three appeared actually very sensitive to OphA-induced necrotic effects (Fig. 4C). It thus seems that OphA-induced modifications in cancer cell size is somewhat paralleled with OphA-induced early and/or late apoptosis vs. necrosis.

Poly(ADP-ribose) polymerase (PARP) is inactivated in apoptosis due to cleavage caused by the caspase signalling pathway. Therefore, cleaved PARP expression levels after $24 \mathrm{~h}$ of $1 \mu \mathrm{M}$ OphA treatment were investigated using western blot analyses in the eight cancer cell lines under study. RD and RH30 rhabdomyosarcoma cells showed an extremely large increase in cleaved PARP expression after treatment with OphA, while such an increase was not apparent in the remaining six cancer cell lines (Fig. 4D).

Taken together, the data illustrated in Figs. 2-4 strongly suggest that OphA-induced growth inhibition of various cancer cell lines (Fig. 2) in vitro may arise through diverse cell death mechanisms.
Mitochondria sensitivity to OphA in cancer cells

Mitochondrial size and branching network. Mitochondria are known to be implicated in cell death, and we therefore studied the effect of OphA on mitochondrial area, size and branching network. To examine this we used an IN Cell ${ }^{\mathrm{TM}}$ high throughput microscopy system to detect mitochondria stained with TOM20. There was a very significant $(\mathrm{P} \leq 0.005)$ decrease of $13 \pm 1,8 \pm 1$ and $17 \pm 1 \%$ in mitochondrial area per cell compared to the control for MDA-MB-231, MCF 7 and HeLa cells when treated with $1 \mu \mathrm{M}$ OphA, respectively (Fig. 5A). Conversely, there was a very significant $(\mathrm{P} \leq 0.005)$ increase in mitochondrial area per cell of $7 \pm 2$ and $45 \pm 3 \%$ for U2OS and U-87 MG cells, respectively, compared to the control (Fig. 5A). There was no significant change in mitochondrial area per cell for RD, RH30 and KB 3-1 cells (Fig. 5A).

In all cell lines tested, the mitochondria became shorter after treatment with OphA as shown by the increase in the proportion of the mitochondria which are short compared to the number which were long (data not shown). Lastly, there was a suggestion that there was an increase in the number of mitochondrial bifurcations after OphA treatment for MCF 7, HeLa, KB 3-1, U2OS and U-87 MG cells (Fig. 5B). However, 


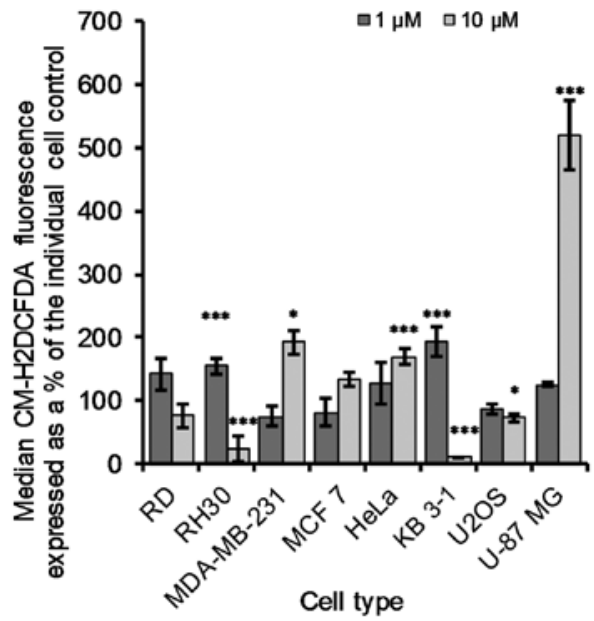

Figure 7. Effect of OphA on reactive oxygen species production measured using $\mathrm{CM}-\mathrm{H}_{2}$ DCFDA. Flow cytometric results for each cell line showing the change in $\mathrm{CM}-\mathrm{H}_{2} \mathrm{DCFDA}$ fluorescence after $1 \mathrm{~h}$ of treatment with 1 and $10 \mu \mathrm{M}$ OphA. Data are presented as mean \pm SD of triplicate samples for each individual cell line expressed as a percentage of the untreated cells. Significance was tested using a two tailed t-test compared to the untreated cells for each line $\left({ }^{*} \mathrm{P} \leq 0.05,{ }^{* * *} \mathrm{P} \leq 0.005\right)$.

higher resolution than provided by the IN Cell ${ }^{\mathrm{TM}}$ is required to confirm this.

Altogether these data nevertheless indicate that mitochondria in cancer cells are sensitive to OphA-induced growth inhibitory effects, while OphA-induced effects on cancer cell mitochondria differ from one cancer cell line to another (Fig. 5).

Mitochondrial membrane depolarization. In addition to the effect of OphA on mitochondrial morphology, mitochondrial function was also investigated in cancer cells treated with OphA. Active mitochondria were stained with tetramethylrhodamine (TMRM) while all the mitochondria were stained with MitoTracker ${ }^{\circledR}$ Green (Fig. 6A). Immunofluorescence images of control RD rhabdomyosarcoma cells show co-localisation of the MitoTracker Green and the TMRM indicating that all the mitochondria have been stained and are active (Fig. 6A). After $1 \mathrm{~h}$ treatment with $1 \mu \mathrm{M}$ OphA the TMRM fluorescence was similar to the control (Fig. 6A). However, after treatment with $10 \mu \mathrm{M}$ OphA TMRM fluorescence had disappeared showing that the mitochondria had been deactivated (Fig. 6A). The fluorescence intensity of the TMRM is related to the mitochondrial membrane potential $\Delta \psi \mathrm{m}$, therefore, we used flow cytometry to quantify the change in $\Delta \psi \mathrm{m}$ after $1 \mathrm{~h}$ OphA treatment (Fig. 6B). There was a significant increase $(\mathrm{P} \leq 0.05)$ of $40 \pm 18$ and $22 \pm 12 \%$ in $\Delta \psi \mathrm{m}$ after $1 \mu \mathrm{M}$ treatment in RH30 and U2OS cells, respectively, compared to the untreated cells indicating hyperpolarization (Fig. 6B). However, there was a significant $(\mathrm{P} \leq 0.05)$ decrease of at least $24 \pm 10 \%$, in $\Delta \psi \mathrm{m}$ after $10 \mu \mathrm{M}$ OphA treatment for all cell lines except MDA-MB-231 and KB 3-1 cells indicating depolarisation of the mitochondrial membrane potential (Fig. 6B).

Generation of reactive oxygen species (ROS). ROS are constantly produced in cells that metabolize oxygen. Mitochondria are believed to be the major intracellular source of ROS and it is estimated that between 0.1 and $4.5 \%$ of ROS escape from the mitochondria into the cytoplasm. This means that $10^{9}$ ROS may arise in the cytoplasm per cell per day by this route alone (32). While ROS are used for cell signalling, excessive production can cause damage to cell organelles. To determine whether OphA treatment induced increased ROS, cells were incubated with the drug for $1 \mathrm{~h}$ and the fluorescent dye $\mathrm{CM}-\mathrm{H}_{2}$ DCFDA used to quantify ROS. Immunofluorescence images of cells which were healthy and adherent to the bottom of the plate showed no $\mathrm{CM}-\mathrm{H}_{2} \mathrm{DCFDA}$ fluorescence while the cells which had rounded up showed high $\mathrm{CM}-\mathrm{H}_{2}$ DCFDA fluorescence (data not shown). After treatment with $1 \mu \mathrm{M}$ OphA the majority of the cells showed low CM- ${ }_{2}$ DCFDA fluorescence while after treatment with $10 \mu \mathrm{M}$ OphA cells appear rounded up and higher $\mathrm{CM}-\mathrm{H}_{2} \mathrm{DCFDA}$ fluorescence was observed (Fig. 7). Quantification of the CM-H ${ }_{2}$ DCFDA fluorescence was performed by flow cytometry and showed that the basal ROS production varied between cell lines (data not shown). There was a significant $(\mathrm{P} \leq 0.05)$ decrease of $17 \pm 7 \%$ in $\mathrm{CM}-\mathrm{H}_{2}$ DCFDA fluorescence for U2OS cells treated with $10 \mu \mathrm{M}$ OphA compared to the control cells (Fig. 7). After $10 \mu \mathrm{M}$ OphA treatment in RD, RH30 and KB 3-1 cells there was a decrease in CM- $\mathrm{H}_{2}$ DCFDA fluorescence (Fig. 7), which was due to the majority (at least 97\%) of the cells being dead and the remaining cells had low $\mathrm{CM}-\mathrm{H}_{2} \mathrm{DCFDA}$ fluorescence. The remaining cells all showed a significant increase in ROS production at either 1 or $10 \mu \mathrm{M}$ OphA treatment (Fig. 7). U-87 MG glioma cells showed the largest increase in ROS generation with an increase of $420 \pm 55 \%$ after $1 \mathrm{~h}$ of $10 \mu \mathrm{M}$ OphA treatment compared to the control cells (Fig. 7).

OphA-induced effects on the endoplasmic reticulum (ER). Functional and morphological evidence indicates that mitochondria are in close contact with the ER (33) and that the proximity of the two organelles may serve to control mitochondrial morphology through the regulation of calcium levels. It could therefore be instructive to investigate the effect of OphA on the ER in more detail. In a similar manner to autophagy, the ER stress response is another adaptive mechanism to support cell survival in response to detrimental conditions such as low nutrient levels, hypoxia, calcium imbalance or the accumulation of misfolded proteins (34). When the stress conditions become too long or too severe, the response activates cell death pathways, as is also seen in autophagy. However, under less severe conditions, ER stress responses and the UPR, may actually increase tumour cell survival (34). There are three main pathways of the ER stress response which are initiated by three sensor proteins located on the ER membrane: i) the inositol-requiring transmembrane kinase and endonuclease (IRE1); ii) activating transcription factor 6 (ATF6); and iii) protein kinase-like ER kinase (PERK) $(31,35)$.

ER swelling. The change in ER total area was measured using an automated high throughput image acquisition and analysis system (IN Cell ${ }^{\mathrm{TM}}$ Analyzer). The ER was stained with calnexin and the IN Cell Analyser Toolbox software was used to determine the change in ER area after $24 \mathrm{~h}$ of treatment with $1 \mu \mathrm{M}$ OphA. There was a very significant increase $(\mathrm{P} \leq 0.005)$ in the ER area per cell after treatment for all cell lines except RD and MDA-MB-231 (Fig. 8A). 

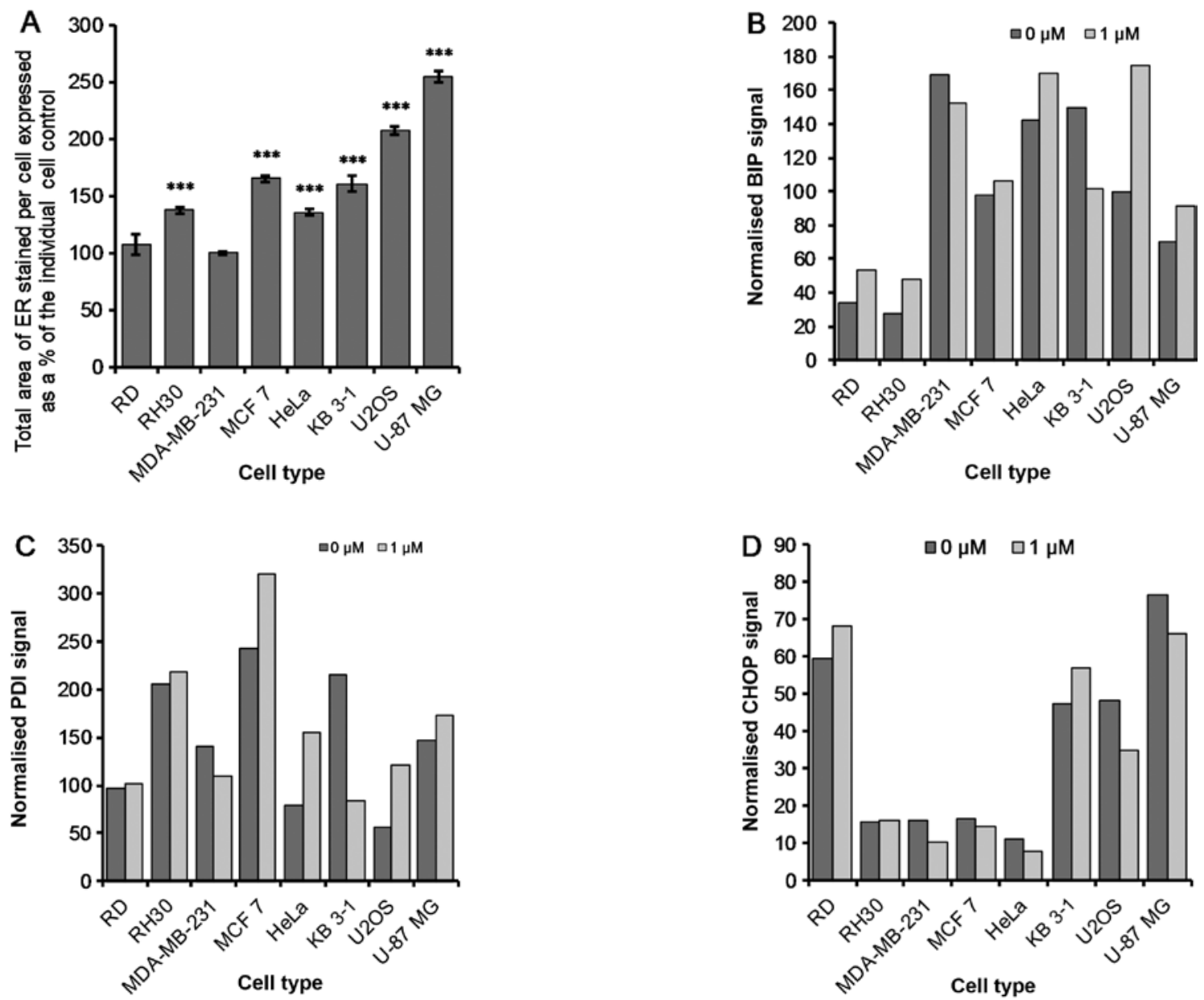

Figure 8. The effects of OphA on the endoplasmic reticulum. (A) The induction of endoplasmic reticulum (ER) swelling. Results showing the change in area of the ER per cell measured using an automated high throughput image acquisition and analysis system. The data are presented as mean \pm SE of between 435 and 1915 cells per sample run in triplicate for each individual cell line expressed as a percentage of the untreated cells. Significance was tested using a two tailed t-test compared to the untreated cells for each line $\left({ }^{* * *} \mathrm{P} \leq 0.005\right)$. (B-D) Graphical representation of western blot data indicating that OphA induced an ER survival response. Data are normalised with respect to $\beta$-actin expression (B) BIP (C) PDI (D) CHOP.

The ER stress response was probed using immunoblotting and antibodies for analysing BiP/GRP78, PDI and CHOP expression, three proteins which are implicated in ER stress response (34) as detailed in the Discussion. The current data show that OphA $(1 \mu \mathrm{M})$ : i) weakly increased BiP/GRP78 expression in RD, RH30, HeLa and U-87 MG cancer cell lines; ii) markedly increased it in U2OS cancer cells; iii) remained without clear effects in MDA-MB-231 and MCF 7 cancer cells; while iv) it decreased BiP/GRP78 expression in KB 3-1 cancer cells (Fig. 8B).

The current data also show that OphA $(1 \mu \mathrm{M})$ : i) displayed no apparent effects on PDI expression in RD, RH30, MDA-MB-231 and U-87 MG cancer cells; ii) increased its expression in MCF 7, HeLa and U2OS; while iii) it decreased it in KB 3-1 cancer cells (Fig. 8C). Lastly, the current data show that OphA $(1 \mu \mathrm{M})$ displayed weak, if any, effects on CHOP expression in the eight cancer cell lines under study (Fig. 8D).

Intracellular calcium concentrations $\left[\mathrm{Ca}^{2+}\right] i$. The most important intracellular calcium store in the cell $\left[\mathrm{Ca}^{2+}\right] \mathrm{i}$ is the $\mathrm{ER}$, and OphA is known to inhibit the calcium binding protein calmodulin in plant cells (15). We therefore, investigated whether there was a change in calcium concentrations in the cancer cells under study after treatment. Cancer cells were pre-stained with a calcium sensitive dye Fluo-4 AM, OphA treatment was applied and the change in Fluo-4 fluorescence was monitored over time. There was an increase in fluorescence (thus an OphA-induced $\left[\mathrm{Ca}^{2+}\right]$ i release) with time for all samples measured. An example of OphA induced $\left[\mathrm{Ca}^{2+}\right]$ i for the RH30 rhabdomyosarcoma cell line is provided for reference (Fig. 9A). The remaining individual $\left[\mathrm{Ca}^{2+}\right]$ i-related curves with respect to the other seven cancer cell lines were also determined (data not shown). The maximum rate of change of the Fluo4 fluorescence (i.e. $\left[\mathrm{Ca}^{2+}\right]$ i) was quantified (Fig. 9B) from the data collected (Fig. 9A and data not shown). After $6 \mathrm{~h}$ of $10 \mu \mathrm{M}$ treatment with OphA all the cancer cell lines showed either an increase or no significant change from the control (Fig. 9B). In particular, RH30 and MDA-MB-231 showed very large increases in the rate of change of $\left[\mathrm{Ca}^{2+}\right] \mathrm{i}$ after incubation with $10 \mu \mathrm{M}$ OphA, and RD and U-87 MG also showed significant increases.

\section{Discussion}

Cell death can be triggered by a range of intracellular stresses such as DNA damage, oxidative stress, cytosolic $\mathrm{Ca}^{2+}$ overload 
A

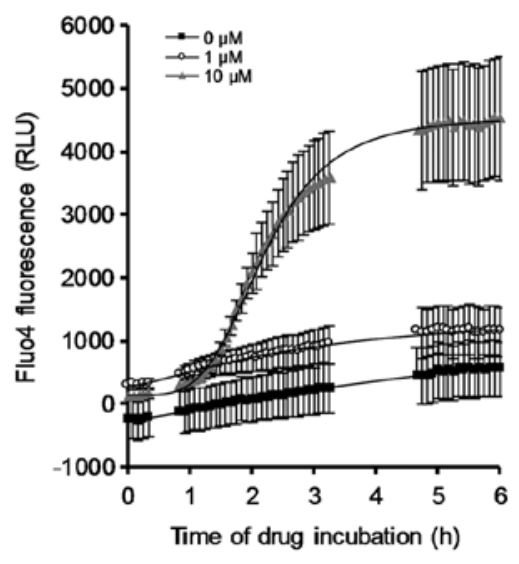

B

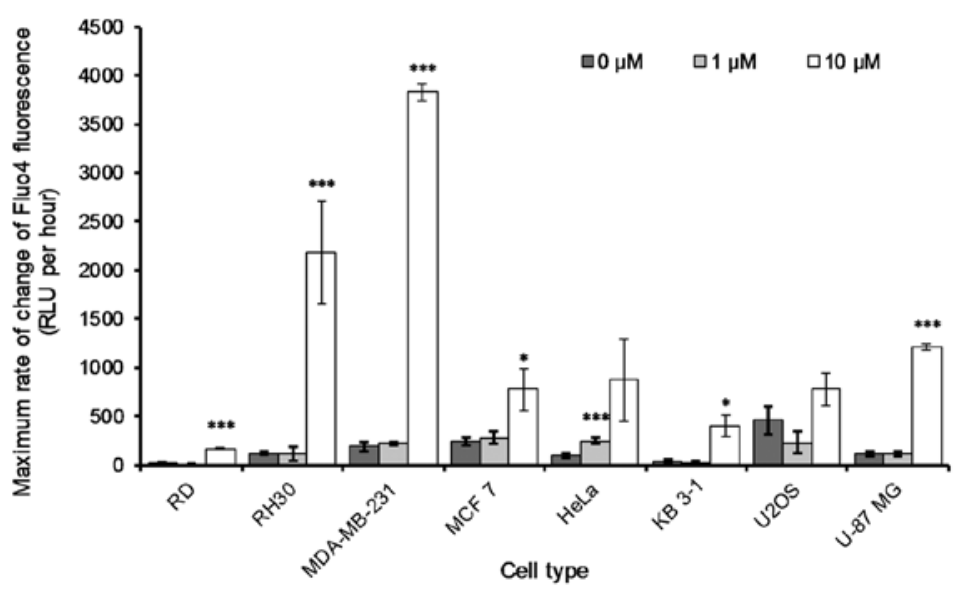

Figure 9. Effect of OphA on cell calcium concentration measured using Fluo4. (A) Results showing the change in Fluo4 fluorescence for RH30 cells with time after treatment with either: i) PBS (black squares); ii) $1 \mu \mathrm{M}$ OphA (dark grey circles); ii) $10 \mu \mathrm{M}$ OphA (light grey triangles) (data not shown for other cell lines). Logistic curves have been fitted to all the data with R2 values $>0.9$ for all cell lines except KB 3-1. (B) Results showing the maximum rate of change of Fluo4 fluorescence after treatment with OphA. The data are presented as mean \pm SD of triplicate samples for each individual cell line. Significance was tested using a two tailed t-test compared to the untreated cells for each line $\left({ }^{*} \mathrm{P} \leq 0.05,{ }^{* * *} \mathrm{P} \leq 0.005\right)$.

and the accumulation of misfolded proteins (22). The ability of OphA to induce cell death on eight human cancer cell lines was investigated. Subsequently, the effects of OphA on cell, mitochondrial and ER morphology were studied. Lastly, we investigated the ability of OphA to modify $\left[\mathrm{Ca}^{2+}\right] \mathrm{i}$, and the ER stress/UPR responses in the eight cancer cell lines under study. A qualitative summary of the data for all eight cell lines tested is presented in Table I.

OphA induced cell death (crystal violet assay) with $\mathrm{LD}_{50}$ (lethal dose) values ranging between submicromolar and low micromolar concentrations after having cultured the various cancer cell lines in the absence (control) or the presence of OphA (Table I). The $\mathrm{LD}_{50}$ values reported here for OphA match closely with the $\mathrm{GI}_{50}$ (growth inhibitory concentration) data reported by the National Cancer Institute (NCI, Bethesda, MD, USA) Natural Product Repository.

Flow cytometric analyses relating to Annexin V/propidium iodide staining revealed that of the eight cancer cell lines under study, five of them (RD, RH30, MDA-MB-231, MCF 7 and HeLa) underwent apoptosis following treatment with $10 \mu \mathrm{M}$ OphA, while the remaining three cancer cell lines (KB 3-1, U2OS and U-87 MG) underwent necrosis (Table II). Of the five cancer cell lines that underwent apoptosis following OphA treatment, two of them (the rhabdomyosarcoma lines RD and RH30) displayed marked PARP cleavage, a feature not observed in the remaining cancer cell lines (Table II). Therefore, the possibility remains that OphA can induce caspase-dependent vs. caspase-independent cell death in those cancer cell lines in which OphA-induced apoptosis was observed. Thus, while the $\mathrm{LD}_{50}$-related values of OphA in the eight cancer cell lines under study were relatively similar (i.e. in the single digit micromolar concentrations), OphA seems to induce caspase-dependent or caspase-independent apoptosis or necrosis depending on the cancer cell line analysed (Table II).

Cell size monitoring permitted the distinction of two groups of cancer cell lines, e.g. those cancer cell lines whose size decreased under OphA treatment and that underwent apoptosis (early and/or late), including both rhabdomyosarcoma lines (RD and RH30) and both breast cancer lines (MDA-MB231 and MCF 7), but not HeLa models, compared to those cell lines whose size increased during OphA treatment and that underwent necrosis, including the KB 3-1, U2OS and U-87 MG models (Table II). It thus seems that an OphA-induced decrease in cell size is related to OphA-induced apoptosis in cancer cells. Such a feature has previously been observed with other phytotoxins in cancer cells including, for example, sphaeropsidin A (SphA) that induces apoptosis in cancer cells through marked cell volume decrease (36). The SphA-induced cell volume decrease in cancer cells occurs via the modulation of ion-transporter activity with increased selectivity for melanoma and kidney cancer cell lines in the NCI-60 panel (36). OphA also modulates the activity of ion channel activity, including the big conductance $\mathrm{Ca}^{2+}$-activated $\mathrm{K}^{+}$channel (BKCa), which results in the activation of paraptosis in apoptosis-resistant glioblastoma cells (7). These impairments of the so-called regulatory volume decrease (RVD) could make SphA (36) and OphA (7) efficient compounds against multidrug resistant (MDR) cancer cells.

Okada et al (37) emphasized that a fundamental property of animal cells is the ability to regulate their own cell volume and that even under hypotonic stress imposed by either decreased extracellular or increased intracellular osmolarity, the cells can re-adjust their volume after transient osmotic swelling by the RVD mechanism. They report that osmotic swelling results in a significant increase in the $\left[\mathrm{Ca}^{2+}\right] \mathrm{i}$ concentration (37). Intracellular $\left[\mathrm{Ca}^{2+}\right] \mathrm{i}$ is strictly regulated in cells by a combination of the passive diffusion of calcium into the cell and by active transport of calcium against a concentration gradient (38). An increase in intracellular calcium levels can be a consequence of release from the ER stores, influx of extracellular calcium and/or the release from other organelles such as the mitochondria (39). A decrease in calcium concentration can be due to calcium being pumped out of the cell or 


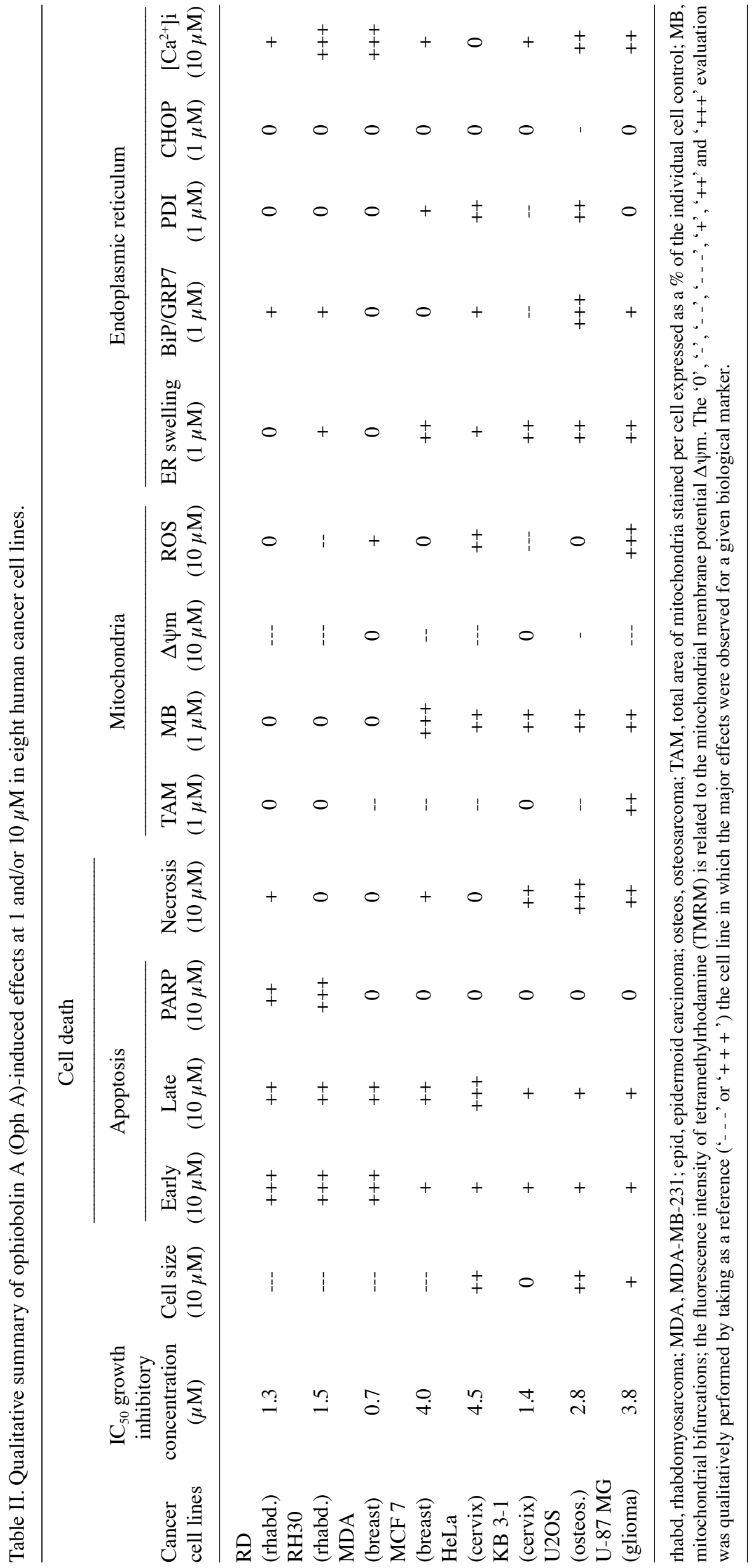




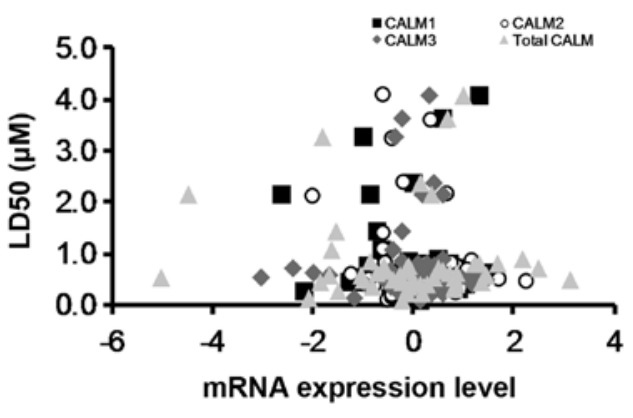

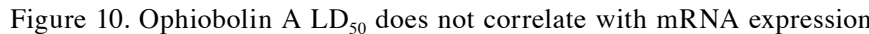
levels. $\mathrm{LD}_{50}$ values were obtained from the NCI-60 DTP Human Tumour cell line screen for Ophiobolin A (Sept 2014) and plotted against the mRNA expression levels of the three calmodulin genes (CALM1, CALM2, CALM3, and total CALM) obtained from cBioPortal for the same NCI-60 cell lines (Sept 2014).

by re-entering the calcium stores in the ER and mitochondria through $\mathrm{Ca}^{2+}$ transport systems. The present study shows that there was a delay of at least $1 \mathrm{~h}$ in calcium being released into the cytosol for all cell lines after OphA treatment compared to the control cells, indicating that OphA affects calcium signalling (Fig. 8; other data not shown). Furthermore, some cell lines showed a huge increase in the amount of cytosolic calcium release after $6 \mathrm{~h}$ of treatment (Fig. 8; other data not shown). In fact, OphA induced $\left[\mathrm{Ca}^{2+}\right] \mathrm{i}$ increases in all cancer cell lines (except for the HeLa cervical carcinoma cell line) (Table I). This point could be more or less related to the fact that while OphA induced marked apoptosis in HeLa cells, it increased HeLa cancer cell size without inducing necrosis (Table II). Kasim et al (40) observed that actinomycin D induced apoptosis and apoptotic volume decrease (AVD) in HeLa cells and that the loss of mitochondrial membrane potential occurred at about the same time as blebbing. In the present study, OphA induced a marked loss of mitochondrial membrane potential in parallel to the observed increase in cell size paralleled by marked apoptosis induction, while it did not alter HeLa-related $\left[\mathrm{Ca}^{2+}\right] \mathrm{i}$ (Table II). Thus, the possibility remains that the kinetics of OphA-induced modifications in all these biological events differ from those in the remaining seven cancer cell lines analysed and that we have missed these events due to the experimental schedules used in the present study.

Historically, it was believed that OphA induced cell death by inhibiting calmodulin (15). However, by obtaining $\mathrm{LD}_{50}$ values from the National Cancer Institute (NCI) Natural Products Repository (41) (Fig. 10) for the NCI cell lines treated with OphA and comparing these to calmodulin mRNA expression levels for the same NCI cell lines from CBioPortal (42) it has been shown that there is no correlation between calmodulin mRNA expression levels and OphA toxicity (Fig. 10). This suggests that, although OphA can inhibit calmodulin, it is not the only molecular target for the molecule. Locato et al (43) reported that ophiobolin A leads to cell cycle arrest at the S/G2 phases in tobacco plants, but also shows the involvement of glutathione and associated redox regulation. It is likely that there are similar mechanisms of action in animal cells.

ROS can be produced by cells in response to stress and can cause damage to proteins, lipids and DNA. Excessive production of ROS results in cell death, for example ROS facilitates the release of cytochrome $c$ from the mitochondria in apoptosis (44). OphA (10 $\mu \mathrm{M})$ significantly decreased ROS production in RH30 and KB 3-1 cancer cells (although this could be a consequence of cell number), but showed little effect in RD, MCF 7 and U2OS cancer cells, while ROS generation increased in MDA-MB-231, HeLa and U-87 MG cancer cells, under the conditions studied. An increase in ROS production (indicating oxidative stress) does not seem to relate to the OphA-induced cell death features observed in the present study. In contrast, OphA reduced $\Delta \psi \mathrm{m}$ in 6 of the 8 cancer cell lines analysed, suggesting that the mitochondria are affected by OphA in most of the cancer cell lines analyzed (although not all); a feature that was confirmed by the quantitative analyses of mitochondria branching (Table I).

A dissipation of the $\Delta \psi \mathrm{m}$ can occur after mitochondrial outer membrane permeabilization (MOMP) through the uncoupling of the mitochondrial respiratory chain or through the opening of the mitochondrial permeability transition (MPT) pore (45). MOMP is commonly associated with apoptosis and the release of toxic proteins into the cytosol. Opening of the MPT causes the mitochondria to become leaky to water and other small molecules which results in mitochondrial swelling eventually leading to necrosis (46). Therefore, while a sustained drop in $\Delta \psi \mathrm{m}$ indicates that the cells are dying it does not elucidate the mechanism of cell death. Bencsik et al (47) also showed that OphA could cause a decrease in the mitochondrial membrane potential in boar spermatozoa.

All the data we have previously accumulated $(6-8,10)$ as well as in the present study (as qualitatively summarized in Table II) suggests that OphA induced major effects in the cancer cell leading either to apoptosis (8) (Table II), paraptosis (7) or necrosis (Table I) and is related to the origin of the cancer cell line analysed (with a panel of more than 10 cancer cell lines analysed in all these studies). However, while OphA induces distinct types of cell death in the various cancer cell lines analysed, its $\mathrm{LD}_{50}$ values remain in the single digit micromolar in all cell lines analysed here (Table I) as well as in our previous studies $(6-8,10)$ a fact that has also been confirmed by the NCI in the 60-cell line panel (SI-4), and that we have also observed in MDR cancer cells (6). It was therefore investigated whether the ER stress response and/or the unfolded protein response (UPR) could be involved in the OphA-induced cell response.

UPR is a survival mechanism of the cell in response to ER stress which occurs when there is an accumulation of unfolded or misfolded proteins in the lumen of the ER (48). Among the major functions of the UPR are to halt protein translation, degrade misfolded proteins and to upregulate the production of molecular chaperones involved in protein folding. Bravo et al (34) also emphasized that the ability to upregulate the UPR during the ER stress response appears to be essential for tumour survival. They state that both the ATF6 and IRE1 pathways induce BiP/GRP78 expression in conditions of ER stress, that BiP/GRP78 promotes ER homeostasis and resistance to apoptosis by interacting with BIK and caspase-7, and that the capacity of IRE1 to sense ER stress depends on its dissociation from BiP/GRP78. Furthermore, an important part of protein synthesis is the folding and the proper assembly of the nascent polypeptide, a process in which the protein 
disulphide isomerase (PDI), which is a thio-oxidoreductase, exerts important roles by catalysing disulphide bond formation. CHOP is a downstream effector in both the ATF6 and PERK pathways and it is actually involved in pro-apoptotic functions (34). The expression levels of BiP/GRP78, PDI and $\mathrm{CHOP}$ were therefore assessed in the present study by western blot analysis. It was shown that OphA induced a very heterogeneous pattern of expression of BiP/GRP78 and PDI in the eight cancer cell lines under investigation (Table I). If the survival mechanism of the UPR fails and the stress encountered is too excessive or too severe then the ER can enlist a death response $(34,49)$ and it seems that this is what occurred with OphA in the present study (Table II). Excessive stress with a weak UPR causes the phosphorylation of PERK and eIF2a which activates the transcription of $\mathrm{CHOP}$, which induces in turn a death response in the mitochondria. OphA was not shown here to increase the protein levels of CHOP in any of the cell lines tested (Table II), although this may be dependent upon the experimental schedule undertaken. However, OphA induced death in all the eight cancer cell lines analysed and it therefore seems that OphA did not allow these cancer cell lines to defend themselves via an ER response and/or UPR against the OphA-mediated cell insults (Table II).

In conclusion, OphA has been shown to induce cell death in all the eight cancer cell lines tested and cell death occurred in these cancer cells via apoptosis (with or without PARP cleavage) or necrosis depending on the cell line analyzed, and appears to be related to the tissue of origin of the cell lines. We have previously shown that OphA is also able to induce paraptosis in apoptosis-resistant glioblastoma cells (7). OphA induced cell death with $\mathrm{LD}_{50}$ values in the single digit micromolar concentration (or even below) in this panel of eight cancer cell lines, a fact that has been confirmed by previous studies as well as in the NCI 60-cell line panel. We have also shown previously that OphA is an efficient compound against MDR cancer cells (6). The present study shows that cancer cells are not able to defend themselves against OphA-induced cytotoxic insults via a successful activation of the ER stress/UPR responses. The current data also point to mitochondria as a central player in OphA-induced cancer cell death, while further studies will be necessary to precisely understand how. However, the fact that OphA is not a selective compound may hamper translation to the clinic. We have already successfully incorporated OphA into mesoporous silica nanoparticles as a potential delivery system (8). We are now working on other systems of OphA vectorization to enable in vivo activity against apoptosis- and/or MDR-resistant cancer models.

\section{Acknowledgements}

The authors thank Dr Maurizio Vurro, Istituo di Scienze delle Produzioni Alimentari, CNR, Bari, Italy, for supplying culture filtrates of Drechslera gigantea. Dr Alan Diot is thanked for his assistance with the IN Cell experiments. We also thank both Professor Alexander Kornienko and Dr Karl Morten for the interesting discussions. R.M. is funded by the RCUK Digital Economy Programme grant number EP/G036861/1 (Oxford Centre for Doctoral Training in Healthcare Innovation). H.T. thanks the Williams fund for their generous research support.

\section{References}

1. Lefranc F, Sadeghi N, Camby I, Metens T, Dewitte O and Kiss R: Present and potential future issues in glioblastoma treatment. Expert Rev Anticancer Ther 6: 719-732, 2006.

2. Mathieu V, de Lassalle EM, Toelen J, Mohr T, Bellahcène A, Van Goietsenoven G, Verschuere T, Bouzin C, Debyser Z, De Vleeschouwer S, et al: Galectin-1 in melanoma biology and related neo-angiogenesis processes. J Invest Dermatol 132: 2245-2254, 2012.

3. Newman DJ and Giddings LA: Natural products as leads to antitumor drugs. Phytochem Rev 13: 123-137, 2014.

4. Shen L, Kondo Y, Ahmed S, Boumber Y, Konishi K, Guo Y, Chen X, Vilaythong JN and Issa JP: Drug sensitivity prediction by $\mathrm{CpG}$ island methylation profile in the NCI-60 cancer cell line panel. Cancer Res 67: 11335-11343, 2007.

5. Dittmann LM, Danner A, Gronych J, Wolter M, Stühler K, Grzendowski M, Becker N, Bageritz J, Goidts V, Toedt G, et al: Downregulation of PRDX1 by promoter hypermethylation is frequent in 1p/19q-deleted oligodendroglial tumours and increases radio- and chemosensitivity of $\mathrm{Hs} 683$ glioma cells in vitro. Oncogene 31: 3409-3418, 2012.

6. Bury M, Novo-Uzal E, Andolfi A, Cimini S, Wauthoz N, Heffeter P, Lallemand B, Avolio F, Delporte C, Cimmino A, et al: Ophiobolin A, a sesterterpenoid fungal phytotoxin, displays higher in vitro growth-inhibitory effects in mammalian than in plant cells and displays in vivo antitumor activity. Int J Oncol 43: 575-585, 2013.

7. Bury M, Girault A, Mégalizzi V, Spiegl-Kreinecker S, Mathieu V, Berger W, Evidente A, Kornienko A, Gailly P, Vandier C, et al: Ophiobolin A induces paraptosis-like cell death in human glioblastoma cells by decreasing BKCa channel activity. Cell Death Dis 4: e561, 2013.

8. Morrison R, Gardiner C, Evidente A, Kiss R and Townley H: Incorporation of ophiobolin a into novel chemoembolization particles for cancer cell treatment. Pharm Res 31: 2904-2917, 2014.

9. de Vries-van Leeuwen IJ, Kortekaas-Thijssen C, Nzigou Mandouckou JA, Kas S, Evidente A and de Boer AH: Fusicoccin-A selectively induces apoptosis in tumor cells after interferon-alpha priming. Cancer Lett 293: 198-206, 2010.

10. Dasari R, Masi M, Lisy R, Ferdérin M, English LR, Cimmino A, Mathieu V, Brenner AJ, Kuhn JG, Whitten ST, et al: Fungal metabolite ophiobolin A as a promising anti-glioma agent: In vivo evaluation, structure-activity relationship and unique pyrrolylation of primary amines. Bioorg Med Chem Lett 25: 4544-4548, 2015.

11. Evidente A, Andolfi A, Cimmino A, Vurro M, Fracchiolla M and Charudattan R: Herbicidal potential of ophiobolins produced by Drechslera gigantea. J Agric Food Chem 54: 1779-1783, 2006.

12. Evidente A, Kornienko A, Lefranc F, Cimmino A, Dasari R, Evidente M, Mathieu V and Kiss R: Sesterterpenoids with anticancer activity. Curr Med Chem 22: 3502-3522, 2015.

13. Kong Au $\mathrm{T}$ and Chow Leung P: Identification of the binding and inhibition sites in the calmodulin molecule for ophiobolin A by site-directed mutagenesis. Plant Physiol 118: 965-973, 1998.

14. Leung PC, Taylor WA, Wang JH and Tipton CL: Ophiobolin A A natural product inhibitor of calmodulin. J Biol Chem 259: 2742-2747, 1984.

15. Leung PC, Taylor WA, Wang JH and Tipton CL: Role of calmodulin inhibition in the mode of action of ophiobolin a. Plant Physiol 77: 303-308, 1985.

16. Fujiwara $H$, Matsunaga $K$, Kumagai $H$, Ishizuka $M$ and Ohizumi Y: Ophiobolin A, a novel apoptosis-inducing agent from fungus strain f-7438. Pharm Pharmacol Commun 6: 427-431, 2000.

17. Heizmann CW, Berchtold MW and Sommer EW: Regulation of calcium in tumor cells. Prog Clin Biol Res 252: 391-394, 1988.

18. Klug M, Blum JK, Ye Q and Berchtold MW: Intracellular $\mathrm{Ca}^{2+}$ and $\mathrm{Ca}^{2+}$-binding proteins in chemically transformed rat fibroblasts. Exp Cell Res 213: 313-318, 1994.

19. Török K, Wilding M, Groigno L, Patel R and Whitaker M: Imaging the spatial dynamics of calmodulin activation during mitosis. Curr Biol 8: 692-699, 1998.

20. Persechini A and Cronk B: The relationship between the free concentrations of $\mathrm{Ca}^{2+}$ and $\mathrm{Ca}^{2+}$-calmodulin in intact cells. J Biol Chem 274: 6827-6830, 1999. 
21. Berchtold MW and Villalobo A: The many faces of calmodulin in cell proliferation, programmed cell death, autophagy, and cancer. Biochim Biophys Acta 1843: 398-435, 2014.

22. Galluzzi L, Vitale I, Abrams JM, Alnemri ES, Baehrecke EH, Blagosklonny MV, Dawson TM, Dawson VL, El-Deiry WS Fulda S, et al: Molecular definitions of cell death subroutines: Recommendations of the Nomenclature Committee on Cell Death 2012. Cell Death Differ 19: 107-120, 2012.

23. Nagaraja GM, Othman M, Fox BP, Alsaber R, Pellegrino CM, Zeng Y, Khanna R, Tamburini P, Swaroop A and Kandpal RP: Gene expression signatures and biomarkers of noninvasive and invasive breast cancer cells: Comprehensive profiles by representational difference analysis, microarrays and proteomics. Oncogene 25: 2328-2338, 2006.

24. Rapa E, Hill SK, Morten KJ, Potter M and Mitchell C: The overexpression of cell migratory genes in alveolar rhabdomyosarcoma could contribute to metastatic spread. Clin Exp Metastasis 29: 419-429, 2012

25. Canal F, Vicent MJ, Pasut G and Schiavon O: Relevance of folic $\mathrm{acid} /$ polymer ratio in targeted PEG-epirubicin conjugates. J Control Release 146: 388-399, 2010.

26. Galluzzi L, Kepp O, Krautwald S, Kroeme and Linkermann A: Molecular mechanisms of regulated necrosis. Semin Cell Dev Biol 35: 24-32, 2014.

27. ATTC (2014) ATCC Cell Lines by Gene Mutation [Online] Available: http://www.atcc.org.

28. Hinson A, Jones R, Crose L, Belyea B, Barr F and Linardic C: Human rhabdomyosarcoma cell lines for rhabdomyosarcoma research:Utility and pitfalls. Front Oncol: 3 183, 2013.

29. Morse D, Gray H, Payne C and Gillies R: Docetaxel induces cell death through mitotic catastrophe in human breast cancer cells. Mol Cancer Ther 4: 1495-1504, 2005.

30. Landry J, Pyl P, Rausch T, Zichner T, Tekkedil M, Stutz A, Jauch A, Aiyar R, Pau G, Delhomme N, et al: The genomic and transcriptomic landscape of a HeLa cell line G3. G3 (Bethesda) $1213-1224,2013$

31. Majno G and Joris I: Apoptosis, oncosis, and necrosis. An overview of cell death. Am J Pathol 146: 3-15, 1995.

32. Beckman KB and Ames BN: The free radical theory of aging matures. Physiol Rev 78: 547-581, 1998.

33. Rizzuto R, Pinton P, Carrington W, Fay FS, Fogarty KE, Lifshitz LM, Tuft RA and Pozzan T: Close contacts with the endoplasmic reticulum as determinants of mitochondrial $\mathrm{Ca}^{2+}$ responses. Science 280: 1763-1766, 1998.

34. Bravo R, Parra V, Gatica D, Rodriguez AE, Torrealba N, Paredes F, Wang ZV, Zorzano A, Hill JA, Jaimovich E, et al: Endoplasmic reticulum and the unfolded protein response: Dynamics and metabolic integration. Int Rev Cell Mol Biol 301: 215-290, 2013.

35. Le Mercier M, Mathieu V, Haibe-Kains B, Bontempi G, Mijatovic T, Decaestecker C, Kiss R and Lefranc F: Knocking down galectin 1 in human hs683 glioblastoma cells impairs both angiogenesis and endoplasmic reticulum stress responses. J Neuropathol Exp Neurol 67: 456-469, 2008.

36. Mathieu V, Chantôme A, Lefranc F, Cimmino A, Miklos W, Paulitschke V, Mohr T, Maddau L, Kornienko A, Berger W, et al: Sphaeropsidin A shows promising activity against drug-resistant cancer cells by targeting regulatory volume increase. Cell Mol Life Sci 72: 3731-3746, 2015.
37. Okada Y,Maeno E, Shimizu T, Dezaki K, Wang J and Morishima S: Receptor-mediated control of regulatory volume decrease (RVD) and apoptotic volume decrease (AVD). J Physiol 532: 3-16, 2001.

38. Florea AM and Büsselberg D: Cisplatin as an anti-tumor drug: Cellular mechanisms of activity, drug resistance and induced side effects. Cancers (Basel) 3: 1351-1371, 2011.

39. Gronski MA, Kinchen JM, Juncadella IJ, Franc NC and Ravichandran KS: An essential role for calcium flux in phagocytes for apoptotic cell engulfment and the anti-inflammatory response. Cell Death Differ 16: 1323-1331, 2009.

40. Kasim NR, Kuželová K, Holoubek A and Model MA: Live fluorescence and transmission-through-dye microscopic study of actinomycin D-induced apoptosis and apoptotic volume decrease. Apoptosis 18: 521-532, 2013.

41. 'LC50 mean graph for compound 114340', Sept 2014. [Online]. Available: https://dtp.cancer.gov/dtpstandard/subsets/comp.jsp.

42. Reinhold WC, Sunshine M, Liu H, Varma S, Kohn KW, Morris J, Doroshow J and Pommier Y: CellMiner: A web-based suite of genomic and pharmacologic tools to explore transcript and drug patterns in the NCI-60 cell line set. Cancer Res 72: 3499-3511, 2012.

43. Locato V, Uzal E, Cimini S, Zonno M, Evidente A, Micera A, Foyer C, De Gara L: Low concentrations of the toxin ophiobolin A lead to an arrest of the cell cycle and alter the intracellular partitioning of glutathione between the nuclei and cytoplasm. J Exp Bot 66: 2991-3000, 2015

44. Atlante A, Calissano P, Bobba A, Azzariti A, Marra E and Passarella S: Cytochrome c is released from mitochondria in a reactive oxygen species (ROS)-dependent fashion and can operate as a ROS scavenger and as a respiratory substrate in cerebellar neurons undergoing excitotoxic death. J Biol Chem 275: 3715937166, 2000.

45. Green DR and Kroemer G: The pathophysiology of mitochondrial cell death. Science 305: 626-629, 2004.

46. Behar SM, Martin CJ, Booty MG, Nishimura T, Zhao X, Gan HX, Divangahi $\mathrm{M}$ and Remold HG: Apoptosis is an innate defense function of macrophages against Mycobacterium tuberculosis. Mucosal Immunol 4: 279-287, 2011.

47. Bencsik O, Papp T, Berta M, Zana A, Forgó P, Dombi G, Andersson MA, Salkinoja-Salonen $M$, Vágvölgyi $C$ and Szekeres A: Ophiobolin A from Bipolaris oryzae perturbs motility and membrane integrities of porcine sperm and induces cell death on mammalian somatic cell lines. Toxins (Basel) 6 : 2857-2871, 2014

48. Liu H, Zhao S, Zhang Y, Wu J, Peng H, Fan J and Liao J: Reactive oxygen species-mediated endoplasmic reticulum stress and mitochondrial dysfunction contribute to polydatin-induced apoptosis in human nasopharyngeal carcinoma CNE cells. J Cell Biochem 112: 3695-3703, 2011.

49. Schonthal AH: Targeting endoplasmic reticulum stress for cancer therapy. Front Biosci (Schol Ed) 4: 412-431, 2012. 